D.E.L.T.A., Vol. 15, N. ${ }^{\circ}$ EsPECIAL, 1999 (165-180)

\title{
O Desenvolvimento da Lingüística Textual no Brasil
}

(The Development of Text Linguistics in Brazil)

Ingedore G. Villaça Косн (Universidade de Campinas)

ABSTRACT: The scope of this paper is to present a critical review of what has been done in the field of Textlinguistics, mainly in Brazil, in the second half of the century and to point out some of the perspectives for new developments in this area.

KEY WORDS: Text Linguistics; Developments; Restrospective; Research in the Field; Main Research Groups.

Palavras-Chave: Lingüística Textual; Desenvolvimentos; Retrospectiva; Pesquisa na Área; Principais Grupos de Pesquisa.

\section{Introdução}

É no final da década de 70 que começam a surgir, no Brasil, os primeiros trabalhos dedicados ao estudo lingüístico do texto. Pode-se dizer que, para tal fato, contribuiu, de forma bastante significativa, a tradução de duas obras: Semiótica Narrativa e Textual (Chabrol et al., 1977) e Lingüística e Teoria do Texto (Schmidt, 1978), bem como a publicação, em Portugal, do livro Pragmática Lingüística e o Ensino do Português (Fonseca \& Fonseca, 1977), no qual se defendia a aplicação dos princípios da Pragmática Lingüística ao ensino de língua materna e, em decorrência, a necessidade de um enfoque textual, como já era comum em outros países da Europa.

Paralelamente, desenvolviam-se, na UNICAMP (Universidade Estadual de Campinas, São Paulo, Brasil), os primeiros importantes estudos sobre o discurso e sobre Semântica Argumentativa, muitos deles publicados sob a forma de livros (Osakabe, 1979; Vogt, 1977) ou de artigos em revistas especializadas. Cumpre destacar também, nesse momento, os trabalhos de Pontes sobre as estruturas de tópico no português brasileiro, posteriormente coletadas nas obras Sujeito: da Sintaxe ao Discurso (São Paulo, Ed. Ática, 1986) e O Tópico no Português do Brasil (Campinas, Ed. Pontes, 1987).

Somente na década de 80, contudo, começam a multiplicar-se os estudos em Lingüística Textual. Após a publicação, na Revista Letras de Hoje, da Pontifícia Universidade Católica do Rio Grande do Sul, de um artigo pioneiro 
de Ignácio Antônio Neis (Por uma Gramática Textual, 1981), inspirado em textos de autores franceses, vêm à luz os dois primeiros livros na área, em 1983: Lingüística Textual: Introdução (Fávero \& Koch) e Lingüística de Texto: O Que é e Como se Faz (Marcuschi). Muitas revistas passam a trazer artigos desenvolvidos sob essa perspectiva, surgindo mesmo números integralmente dedicados aos estudos textuais (cf., por exemplo, Letras de Hoje 18 (2), Cadernos PUC 22: Lingüística Textual/ Texto e Leitura). Em anais de congressos e seminários começam a proliferar trabalhos desenvolvidos nesse domínio.

Em várias universidades brasileiras vão-se formando núcleos de pesquisa sobre texto. A pesquisa na área frutifica em cursos de extensão, aperfeiçoamento e especialização, ministrados em diversos pontos do país, bem como em dissertações de mestrado e teses de doutorado, cujos autores, subseqüentemente, vão implantando esse tipo de enfoque em suas instituições de origem.

\section{Principais perspectivas teóricas}

As pesquisas sobre texto realizadas no Brasil inspiram-se fortemente em estudos realizados na Alemanha (Weinrich, Dressler, Beaugrande \& Dressler, Gülich \& Kotschi, Heinemann \& Viehweger, Motsch \& Pasch, entre outros); na Holanda (Van Dijk); na França (Charolles, Combettes, Adam, Vigner, Coste, Moirand etc.), na Inglaterra (particularmente por Halliday \& Halliday \& Hasan) e nos EUA, tanto por lingüistas (Chafe, Givón, Prince, Thompson, Webber, Brown \& Yule), como por psicólogos e pesquisadores em Inteligência Artificial (Clark \& Clark, Minsky, Johnson-Laird, Sanford \& Garrod, Rumelhart, Schank \& Abelson, Marslen-Wilson e outros), além, é claro, daqueles realizados no interior do funcionalismo praguense (Daneš, Firbas, etc.); e, na década de 90, pesquisas sobre anáfora e referência que se vêm efetivando na França, no bojo do projeto L'Anaphore et son traitement, financiado pelo Programa Cognisciences, Pir-Cnrs (Charolles, Kleiber, Mondada, Dubois) e por Apothéloz, Reichler-Béguelin Berrendonner, entre vários outros), na Suíça (Fribourg, Neuchâtel).

\subsection{Primeiro momento}

Na primeira metade da década de oitenta, publicaram-se em nosso país obras introdutórias, que visavam não só a apresentar ao leitor brasileiro esse ramo da ciência lingüística, seus objetivos, pressupostos e categorias de análise, 
como traçar um panorama geral do que se vinha fazendo nesse domínio em outros países (Lingüística de Texto: O Que é e Como se Faz, de Luiz Antônio Marcuschi e Lingüística Textual: Introdução, de Ingedore G. Villaça Koch \& Leonor L. Fávero, ambos publicados em 1983, além do artigo de Neis, acima mencionado). Em 1984, por ocasião da reunião anual da Sociedade Brasileira para o Progresso da Ciência (SBPC), realizou-se, pela primeira vez, uma mesaredonda sobre lingüística do texto, com o tema "Coerência e Coesão na Teoria do Texto", da qual fizeram parte Marcuschi, Neis e Koch. Desde então, em todos os congressos e reuniões científicas, a lingüística textual passou a ter o seu lugar.

Os aspectos mais enfatizados nessa época, como também na segunda metade da década de 80, foram: os critérios ou padrões de textualidade propostos por Beaugrande \& Dressler (1981), especialmente a coesão textual, esta enfocada em geral sob a perspectiva de Halliday \& Hasan (1976), mas inspirando-se, também, nos estudos da escola funcionalista de Praga (particularmente, Daneš) quanto às questões de progressão temática; a coerência textual; a intertextualidade; a tipologia de textos; a produção/ compreensão/ sumarização de textos; os mecanismos de conexão (conectores semânticos e pragmático/discursivos); outros processos lingüísticos vistos sob a ótica textual (topicalização, referenciação, nominalização, tempos verbais; emprego do artigo, etc.).

Em 1985, publica-se Coesão e Coerência em Narrativas Escolares Escritas (Lúcia M. K. Bastos, Campinas: Editora da Unicamp). É também a partir de então que revistas especializadas e anais de congressos passam a trazer artigos e comunicações sobre os vários critérios ou fatores de textualidade, com destaque para a coesão, a coerência, a intertextualidade, a informatividade, a situacionalidade, a argumentatividade, bem como sobre o emprego dos tempos verbais e as tipologias textuais.

Como foi dito acima, grande parte dos trabalhos dessa primeira fase fundamentou-se em Halliday \& Hasan (1976), no tocante à coesão e em Beaugrande \& Dressler (1981), no que se refere aos fatores de textualidade. Contudo, os pesquisadores brasileiros não somente passam a proceder a uma revisão crítica de tais critérios, acrescentando vários outros, como também, principalmente, postulam que se deixe de considerar a coerência apenas como um fator, entre os demais, para entendê-la como um macro-fator da textualidade, resultante da atuação conjunta de todos os demais fatores e, portanto, decisiva para a caracterização da textualidade (cf. Marcuschi, 1983; Koch, 1984, 1985, 
1986, 1987, 1988; Koch \& Fávero, 1985; Fávero, 1985).

A pesquisa sobre o emprego textual dos tempos verbais fundamentouse, basicamente, na teoria de Harald Weinrich (1964, 1968, 1971). Todos os estudos que se fizeram e (fazem) sobre o tema tomam sua obra como pressuposto principal, embora, evidentemente, se lhe façam alguns questionamentos de ordem geral e se apontem inadequações da teoria quando aplicada ao português (cf., por exemplo, Koch, 1982, 1984, 1992).

Quanto aos tipos de texto, a influência mais forte foi a de Van Dijk. Seu conceito de superestrutura, aplicado à descrição de diversos tipos de textos, teve grande aceitação no Brasil, tendo inspirado trabalhos bastante instigantes. O mesmo ocorreu com o conceito de macroestrutura e a descrição das estratégias de sumarização, que foram aplicadas não só em uma série de trabalhos sobre compreensão e produção de textos e sobre a produção de resumos, publicados em livros e revistas especializadas, como também em diversas teses e dissertações orientadas pelos pesquisadores que atuam na área da Lingüística Textual.

\subsection{Segundo momento}

Em 1989, vêm à luz as obras A Coesão Textual (Koch, São Paulo: Ed. Contexto) e Texto e Coerência (Koch \& Travaglia, São Paulo, Ed. Cortez), seguidas, em 1990, de A Coerência Textual (Koch \& Travaglia, São Paulo: Ed. Contexto), que iniciam uma segunda fase dos estudos textuais em nosso país.

Koch (1989), seguindo um percurso que se havia iniciado já em 1986, com o artigo Principais mecanismos de coesão textual em português, afastando-se em parte de Halliday e abeberando-se em trabalhos de autores alemães como Meyer-Hermann (1976) e Kallmeyer(1974), entre outros, passa a classificar os mecanismos de coesão fundamentalmente com base em sua função textual. Distingue, assim, dois grandes grupos de recursos coesivos: os que são responsáveis pela remissão a outros elementos textuais ou inferíveis (coesão remissiva ou referencial) e os que se destinam a tornar possível a progressão textual, garantindo a continuidade de sentidos (coesão seqüencial). Em Koch \& Travaglia $(1989,1990)$, procede-se à conceituação da coerência como um princípio de interpretabilidade do texto, na esteira de Charolles (1987), a partir de três pressupostos básicos: 1. a coerência não constitui mera qualidade ou propriedade do texto em si; 2 . em decorrência de 1 , ela não se confunde com a coesão, a qual não é condição nem necessária nem suficiente 
da coerência; 3 . a coerência resulta da atuação conjunta de uma complexa rede de fatores, de ordem lingüística, cognitiva, sociocultural, interacional etc. Outras obras vêm defender, também, posições semelhantes, como é o caso de Fávero (1991) e de Costa Val (1991).

Também os estudos de E. Gülich, vários deles em co-autoria com T. Kotschi (cf. Gülich \& Kotschi, 1987), influenciaram de forma importante algumas das pesquisas desse período, particularmente aquelas que dizem respeito à formulação textual (veja-se, entre outros, Barros, 1990; Hilgert, 1993).

\subsection{Momento atual}

Já nos primeiros anos da década de 90 delineava-se uma forte inclinação para a adoção de uma perspectiva sócio-interacional no tratamento da linguagem (Geraldi, 1991; Koch, 1992) e, em decorrência, para o estudo dos processos e estratégias sócio-cognitivos envolvidos no processamento textual (quer em termos de compreensão, quer em termos de produção), especialmente por parte de pesquisadores como Marcuschi e Koch. O primeiro, já na segunda metade da década anterior, havia desenvolvido um projeto sobre a produção de inferências, financiado pelo CNPq, cujos resultados foram parcialmente divulgados através de artigos (cf. Marcuschi, 1984, 1994). A segunda, em sua pesquisa intitulada A construção da coerência em textos escritos e orais, também financiada pelo CNPq, investigou também essa questão, que discutiu no artigo A produção de inferências e sua contribuição na construção do sentido (D.E.L.T.A. 9, n. ${ }^{\circ}$ Especial, 1993) .

Tal forma de abordagem dos fenômenos textuais levou a um diálogo crescente com outras Ciências Humanas, como a Psicologia Cognitiva, a Inteligência Artificial, a Neuropsicologia, a Antropologia, a Sociologia Interacional e as Ciências Cognitivas de modo geral.

Os principais objetos de pesquisa, dentro do enfoque mencionado, têm sido a estrutura e o funcionamento da memória, bem como as formas de representação dos conhecimentos, seu acessamento, utilização, recuperação e atualização, por ocasião do processamento de textos; as principais estratégias de ordem sócio-cognitiva, interacional e textual postas em ação durante o processo de produção/ intelecção; e, ainda, as estratégias de 'balanceamento' do implícito/explícito.

Os pesquisadores que estão engajados no estudo dessas questões 
(Marcuschi, 1994, 1995, 1997); Koch, 1996 a, b, 1997 a, b) tomam como fontes obras de autores como Schwarz (1992), Rickheit \& Strohner (1985), Heinemann \& Viehweger (1991), Van Dijk (1989,1994), Vignaux (1991), além de vários outros citados no item 2.

Outra tendência é a que, com base em obras como as de Adam (1990, 1992), bem como naquelas que se dedicam ao estudo dos gêneros textuais, retomam a questão da tipologia textual, a qual, por algum tempo, pareceu relegada a segundo plano. Podem destacar-se aqui as pesquisas de Marcuschi sobre tipologia do texto.

Nesta segunda metade da década de 90 , vem voltando à tona com particular ênfase, em decorrência das pesquisas mencionadas no item 2, caput, a questão da referenciação, isto é, das diversas formas de remissão textual e, em particular, dos vários tipos de recursos anafóricos e de seu processamento sóciocognitivo (Marcuschi, 1994, 1997; Koch, 1996, 1997).

Entre os principais pesquisadores na área da Lingüística Textual, nesse período, além dos acima mencionados, merecem destaque: Luiz Carlos Travaglia, da Universidade Federal de Uberlândia; Clélia Cândida Spinardi Jubran e Mercedes Sanfelice Risso, da Universidade Estadual Paulista (UNESP), campus de Assis; Maria do Rosário Gregolin, da UNESP - campus de Araraquara; Elisa Guimarães e Maria Lúcia Cunha Victório Andrade, da Universidade de São Paulo; Maria Piedade Moreira de Sá, Dóris Carneiro da Cunha, Judith Hoffnagel, da Universidade Federal de Pernambuco; Maria Irandé Antunes, da Universidade Federal de Alagoas; José Gaston Hilgert, da Universidade de Passo Fundo (RS); Sueli Cristina Marquesi, João Hilton Sayeg de Siqueira, Regina Célia Pagliuchi da Silveira, da Universidade Católica de São Paulo; José Luiz Meurer e seu grupo, da Universidade Federal de Santa Catarina; Maria Aparecida Lino Pauliukonis, Helênio Fonseca de Oliveira, Leonor Werneck dos Santos e equipe, da Universidade Federal do Rio de Janeiro. Todos esses pesquisadores têm não só publicado trabalhos na área, como orientado teses e dissertações nesse domínio.

De outra parte, alguns estudiosos vêm aplicando conceitos básicos da Linguiística Textual à alfabetização, à aquisição da escrita e ao ensino de língua, materna ou estrangeira, de modo geral. Entre eles, podem-se mencionar; Massini-Cagliari (1997); Koch (1993, 1994); Milanez (1993); Marcuschi (1993, 1997).

\subsection{Estudo do texto falado}


Outra vertente das pesquisas textuais extremamente importante no Brasil é a que se vem dedicando ao estudo de textos falados. Tais estudos vêm-se realizando, de forma particular, no interior de três grandes projetos: NURC, Censo/Peul e PGPF.

O Projeto de Estudo da Norma Lingüística Urbana Culta (NURC), visando a pesquisar a norma objetiva do português culto falado no Brasil, coletou, no início da década de 70, materiais de três diferentes tipos: elocuções formais (EF), entrevistas (DID) e diálogos entre dois informantes (D2), em cinco capitais brasileiras (São Paulo, Rio de Janeiro, Salvador, Recife e Porto Alegre). Os informantes, divididos em três faixas etárias ( 25 a 35 anos; 36 a 55 anos; 56 anos ou mais), deveriam ter formação universitária completa, ter nascido na cidade em estudo e nela ter vivido, pelo menos, três quartas partes de suas vidas e ser filhos de falantes nativos de português.

Nas décadas de 80 e 90, esse material passou a ser objeto de estudos textuais pelo grupo do NURC-Recife, coordenado por Maria Piedade Moreira de Sá e, em especial, pelo grupo do NURC/SP - Núcleo USP, coordenado por Dino Preti. Deste último fazem parte, entre outros, Hudinilson Urbano, Paulo Gallembeck, Diana Luz Pessoa de Barros, Zilda Maria Zapparoli Melo, Luiz Antônio da Silva, Margaret de Miranda Rosa e Leonor Lopes Fávero, de cujos trabalhos alguns encontram-se reunidos em Preti \& Urbano (1990), Preti (1993) e Preti (1997).

O Projeto Censo da Variação Lingüística do Estado do Rio de Janeiro, que se desenvolveu também na década de 80 e vem tendo continuidade no Programa de Estudos sobre o Uso da Língua (PEUL - UFRJ/CNPq), caracterizase por uma abordagem sociolingüística, que busca uma interface com o discurso. Reúne pesquisadores como Maria Luíza Braga, Anthony Julius Naro, Cláudia Nívea Roncarati, Alzira Tavares de Macedo, Maria Marta Pereira Scherre, Maria Cecília Mollica, Neliza Omena, Helena Gryner, Maria da Conceição Paiva, Maria Eugênia Lamoglia Duarte, Vera Lúcia Paredes P. da Silva, cabendo lembrar, ainda, Giselle Machline de Oliveira e Silva (já falecida), que coordenou o Projeto durante algum tempo e foi uma de suas maiores incentivadoras.

Por fim, o Projeto Gramática do Português Falado (PGPF), idealizado e coordenado por Ataliba Teixeira de Castilho, teve início em 1988, com o objetivo de produzir coletivamente uma gramática de referência do português culto falado no Brasil, com base nos dados do Projeto NURC, acima descrito. Cerca 
de 35 pesquisadores, vinculados a diferentes universidades de todo o país, reagruparam-se, para uma melhor eficácia na condução dos trabalhos, em três projetos temáticos: (i) o de Classes Lexicais e Gramaticais, coordenado por Maria Helena de Moura Neves, que inclui o GT de Morfologia (posteriormente subdividido em Morfologia Derivacional, coordenado por Margarida Basílio, e Morfologia Flexional, coordenado por Ângela Rodrigues) e o de Sintaxe das Classes Gramaticais, sob a coordenação de Rodolfo Ilari; (ii) o de Relações Gramaticais, coordenado inicialmente por Fernando Tarallo, também falecido, e, desde então, por Mary A . Kato, que engloba também o GT de Fonologia e Fonética, sob a coordenação de Maria Bernadete Abaurre; (iii) o de Organização Textual-Interativa, coordenado por Ingedore G. Villaça Koch. Já se encontram publicados seis volumes intitulados Gramática do Português Falado, que reúnem trabalhos produzidos, em grupos ou individualmente, pelos pesquisadores de cada equipe.

Dentre os vários grupos acima mencionados, é no interior do Projeto Temático ‘Organização Textual-Interativa no Português Falado no Brasil' que se têm desenvolvido, dentro da abordagem textual-interativa que o fundamenta e, em decorrência, com a mobilização de conceitos da Lingüística Textual, da Análise da Conversação e da Pragmática Lingüística, as principais pesquisas sobre a natureza do texto falado, sua organização tópica, as estratégias de construção (inserção, parafraseamento, repetição, interrupção, segmentação, correção), os marcadores discursivos e/ou articuladores textuais, as formas de marcação de relevo, etc. Além dos textos incluídos nas coletâneas acima citadas, os membros da equipe (Koch, Risso, Jubran, Marcuschi, Fávero, Urbano, Hilgert, Travaglia, Oliveira e Silva, Souza e Silva, Andrade, Aquino, Crescitelli), bem como outros pesquisadores que neles se inspiraram, têm produzido grande número de trabalhos individuais, publicados em revistas especializadas e/ou apresentados em congressos, nacionais e internacionais.

\section{Conclusão}

Verifica-se que não só a Lingüística Textual, como também estudos sobre o texto realizados à luz de outras perspectivas teóricas, encontraram terreno fértil no Brasil, onde germinaram generosamente e continuam a produzir frutos em abundância.

Ano por ano, novos contingentes vêm engrossando as fileiras desse 'exército' que, reduzido a princípio a alguns poucos voluntários, hoje pode-se dizer que 'se apoderou' de praticamente todas as regiões do país, visto que, 
em grande parte das universidades brasileiras, existem hoje docentes que se dedicam à pesquisa e ao ensino desse ramo da Ciência Lingüística.

Desta forma, tanto as pesquisas sobre textos escritos, como as que se ocupam da construção e elaboração de textos falados vêm ocupando lugar de destaque entre os estudiosos das universidades do país, quer federais, quer estaduais ou particulares e vêm dando origem a um acervo bibliográfico respeitável, tanto em termos quantitativos, como qualitativos.

O quadro continua a se mostrar grandemente promissor, já que muitos dos jovens pesquisadores ligados aos nossos cursos de pós-graduação têm escolhido esta área como campo de atuação, o que certamente garante a continuidade dos estudos nesse domínio.

REFERÊNCIAS BIBLIOGRÁFICAS

Adam, J.-M. (1990) Éléments de linguistique textuelle. Paris: Mardaga. . (1992) Les textes: types et prototypes. Paris: Nathan.

Antunes, I. C. (1996) Aspectos da coesão do texto. Recife: UFPE.

Barros, D. L. P. de \& Z. M. Z. C. Melo (1990) Procedimentos e funções da correção na conversação. In: Preti \& Urbano (orgs.) A linguagem falada culta na cidade de São Paulo. São Paulo: T.A. Queiroz/Fapesp: 13-58.

Bastos, L. M. K. (1985) Coesão e coerência em narrativas escolares escritas. Campinas: Ed. da UNICAMP.

Braga, M. L. (1986) Construções de tópico de discurso. In: A.J.NAro. Relatório final de pesquisa: Subsídios sociolingüísticos do projeto Censo à educação. Rio de Janeiro, UFRJ, vol. 1 e 2.

Beaugrande, R. de \& W. U. Dressler (1981) Introduction to text linguistics. Londres: Longman.

Brown, G. \& G. Yule (1983) Discourse analysis. Cambridge: Cambridge University Press.

Chabrol, C. et alii (1977) Semiótica narrativa e textual. São Paulo: Cultrix. Chafe, W. (1987) Cognitive constraints on information flow. In: R.S. Toulmin (ed.) Coherence and gounding in discourse. Philadelphia: John Benjamins.

Charolles, M. (1983) Coherence as a principle in the interpretation of discourse. Text 3/1: 71-99.

Costa Val, M. da G. (1991) Redação e textualidade. São Paulo: Martins Fontes. 
Cunha, D. A . C. (1995) A heterogeneidade de gêneros discursivos no espaço conversacional. Anais do I Encontro Nacional sobre língua falada e ensino: 421-425.

(1996) O discurso direto como uma estratégia de textualidade na fala. Anais do XI Encontro Nacional da ANPOLL.

Daneš, F. (1974) (org.)Papers on functional sentence perspective. Praga: The Hague.

Dressler, W. U. (1978) (ed.)Current Trends in Linguistics. Berlim: Walter de Gruyter.

FÁvero, L L. (1985) Intencionalidade e aceitabilidade como critérios de textualidade. Cadernos PUC 22: Lingüística textual/ texto e leitura: 31-38.

(1985) A informatividade como elemento da textualidade. Letras de Hoje, 60: 13-20.

(1991) Coesão e Coerência Textuais. São Paulo: Ática.

FÁvero, L. L. \& I. G. V. Koch (1983) Lingüística textual: Introdução. São Paulo: Cortez.

Fávero, L L.; M.L.C.V.O. Andrade; Z.G.O. Aquino (1996) Perguntas e respostas como mecanismos de coesão e coerência. In: A.T. CAstilHo (org.) Gramática do Português Falado IV: Estudos descritivos. Campinas: Edunicamp/Fapesp: 473-508.

(1966) Estratégias de construção do texto falado: a correção. In: M. A. Kato (org.) Gramática do Português Falado V: Convergências. Campinas: Edunicamp/Fapesp: 355-366.

Fonseca, J. \& F. I. Fonseca (1977) Pragmática lingüística e o ensino do português. Coimbra: Almedina.

Geraldi, J. W. (1991) Portos de passagem. São Paulo: Martins Fontes.

Gregolin, M. do R. F. V. (1997) A intervenção de estruturas da fala na produção de textos escritos por crianças em processo de alfabetização. Anais do XXI Congresso Internazionale di Linguistica e Filologia Romanza.

Gryner, H. (1996) Variação modal como estratégia argumentativa. In: Macedo, Roncarati \& Mollica (orgs.) Variação e Discurso. Rio de Janeiro: Tempo Brasileiro: 113-128.

Guimarães, E. (1990) A articulação do texto. São Paulo: Ática.

Gülich, E. \& T. Котschi (1983) Les marqueurs de la reformulation paraphrastique. Cahiers de linguistique française, 5: 305-351.

(1987) Les actes de reformulation dans la consultation 'La Dame de Caluire'. In: P. BANGE (ed.) L'analyse des interactions verbales. $L a$ Dame de Caluire: une consultation: 15-81. 
(1995) Discourse production in oral communication. In: U. M.Quastoff (ed.) Aspects of oral communication. Berlim: De Gruyter: 30-65.

Halliday, M. A .K. \& R. Hasan (1976) Cohesion in English. Londres: Longman.

Heinemann, W. \& D. Viehweger (1991) Textlinguistik: eine Einführung. Tübingen: Niemeyer.

Hilgert, J. G. (1993) Procedimentos de reformulação: a paráfrase. In: D. Preti (ed.) Análise de textos orais. FFLCH/USP.

(1993) Esboço de uma fundamentação teórica para o estudo das atividades de formulação textual. In: A.T. CAstilho (org.) Gramática do Português Falado III: As abordagens. Campinas: Edunicamp/ Fapesp: 99-110.

(1997) As paráfrases na construção do texto falado: o caso das paráfrases em relação paradigmática com suas matrizes. In: I. G. V. Koch (org.) Gramática do Português Falado VI: Desenvolvimentos. Campinas: Edunicamp/Fapesp: 131-148.

HoffNAGEL, J. C. (1996) A modalização epistêmica na construção de sentido: o caso do 'eu acho (que)'. Anais do $6^{\circ}$. INPLA.

(1996) A modalização epistêmica no processamento textual da fala. Anais do XI Encontro Nacional da ANPOLL.

Jubran, C. C. S.; H. Urbano; L. L. Fávero; I. G. V. Koch; M. S. Risso et alii (1992) Organização tópica da conversação. In: R. IlARI (org.) Gramática do Português Falado, 2: Níveis de Análise Lingüística. Campinas: Edunicamp/Fapesp: 357-479.

(1993) Inserção: um fenômeno de descontinuidade na organização tópica. In: A.T. Castilho (org.) Gramática do Português Falado III: As abordagens. Campinas: Edunicamp/Fapesp: 61-74.

(1996) Parênteses: propriedades identificadoras. In: CAstilho \& Basílio (orgs.) Gramática do Português Falado IV: Estudos descritivos. Campinas: Edunicamp/Fapesp: 411-422.

(1996) Por uma descrição textual-interativa das funções da parentetização. In: M. KaTo (org.) Gramática do Português Falado V: Convergências. Campinas: Edunicamp/Fapesp: 339-354.

Kallmeyer, W. et alii. (1974) Lektürekolleg zur textlinguistik. Frankfurt. Косн, I. G. V. (1982) Os tempos verbais no discurso. Ângulo, 13/14: 14-17. (1983) A argumentatividade no discurso. Letras de Hoje, 52 (número monográfico).

(1984) Argumentação e Linguagem. São Paulo: Cortez. (1985) A situacionalidade como elemento da textualidade. Letras de 
Hoje, 18(2): 21-28.

(1986) A intertextualidade como elemento da textualidade. Cadernos PUC 22: Linguística Textual/ Texto e Leitura: 39- 46.

(1987) Dificuldades na leitura/produção de textos: os conectores interfrásticos. In: M. Kirst \& E. Clemente (orgs.) Lingüística Aplicada ao Ensino do Português. Porto Alegre: Mercado Aberto: 83-98.

(1988) Principais mecanismos de coesão textual em português. Cadernos de Estudos Lingüísticos, 15: 73-80. (1989) A Coesão Textual. São Paulo: Contexto. (1990) A propósito: existem mesmo digressões?. Cadernos de Estudos Lingüísticos, 19: 123-126.

(1991) Intertextualidade e polifonia: um só fenômeno? D.E.L.T.A., 7 (2):529-541.

(1992) Markierte Topikkonstruktionen im Brasilianischen Portugiesisch. Folia Linguistica XXVI / 1-2: 62-74.

(1992) A inter-ação pela linguagem. São Paulo: Contexto.

(1992) Visão panorâmica das pesquisas sobre texto no Brasil. Ilha do Desterro, 27: 143-156.

(1993) A atividade de produção textual. Cadernos de Estudos Lingüísticos, 24: 65-74.

(1993) A produção de inferências e sua contribuição na construção do sentido. D.E.L.T.A. 9, número especial: 399-416.

(1994) Coesão e coerência: verso e reverso. In: Morphé, 9/10: 309320.

(1995) A articulação entre orações no texto. Cadernos de Estudos Lingüísticos, 28: 09-18.

(1996) Cognição e processamento textual. Revista da ANPOLL, 2 : 35-44.

(1996) A coesão textual e a construção dos sentidos. In: I. MAgAlHães (org.) As múltiplas faces da linguagem. Brasília: UNB: 79-90.

(1996) Estratégias pragmáticas de processamento textual. Cadernos de Estudos Lingüísticos, 30: 35-42.

(1996) Aquisição da escrita e textualidade. Cadernos de Estudos Lingüísticos, 29: 109-117.

(1997) Funções discursivas da repetição. Actas del I Seminário Interamericano de Analistas do Discurso: 170-176. (1997) O texto e a construção dos sentidos. São Paulo: Contexto. et alii (1990) Aspectos do processamento do fluxo de informação 
no discurso oral dialogado. In: A.T. CAstilho (org.) Gramática do Português Falado, 1: A Ordem: 143-184. Campinas: Edunicamp/ Fapesp: 143-184.

\& L. L. FÁvero (1985) Critérios de textualidade. Veredas, 104: 17-34. (1987) Contribuição a uma tipologia textual. Letras \& Letras, 3(1).

3- 10.

\& L. C. Travaglia (1989) Texto e Coerência. São Paulo: Cortez. (1990) A Coerência Textual. São Paulo: Contexto.

e M. C. P. de Souza e Silva, (1993) A dimensão ilocutória no texto falado. In: A.T. de Castilho (org.) Gramática do Português Falado, 3: As abordagens. Campinas: Edunicamp/Fapesp: 19-33.

(1996) Atividades de composição do texto falado: a elocução formal. In: A.T. Castilho e M. Basílıo (orgs.) Gramática do Português Falado

4: Estudos descritivos. Campinas: Edunicamp/Fapesp: 379-410.

(1996) Estratégias de desaceleração do texto falado. In: M.A.КАто (org.) Gramática do Português Falado, V: Convergências. Campinas: Edunicamp/Fapesp: 327-338.

Marcuschi, L. A. (1983) Lingüística de Texto: o que é e como se faz. Recife:UFPE.

(1984) Leitura como processo inferencial num universo culturalcognitivo. Anais do I Encontro Interdisciplinar de Leitura - UEL: 2144.

(1986) Análise da conversação. São Paulo: Ática.

(1993) O tratamento da oralidade no ensino de língua. São Paulo: Ática.

(1994) Estratégias de identificação referencial na interação face a face. Trabalho apresentado no I Congresso Internacional da ABRALIN.

(1995) Contextualização e explicitude na relação entre fala $e$ escrita. ms.

(1997) A repetição na língua falada como estratégia de formulação textual. In: I. G. V. Kосн (org.) Gramática do Português Falado, VI: Desenvolvimentos. Campinas: Edunicamp/Fapesp: 95-130.

Marquesi, S. C. (1995) A organização do texto descritivo em língua portuguesa. São Paulo: Vozes.

Massini-Cagliari, G. (1997) O texto na alfabetização: coesão e coerência. Campinas: Ed. da Autora.

Meurer, J. L. (1993) Aspectos do processo de produção de textos escritos. 
Trabalhos de Lingüística Aplicada, 21: 37-48.

Meyer-Hermmann, R. (1976) Some topics in the study of referentials in portuguese. In: J. Schmidt-RAdefeld (ed.) Readings in Portuguese Linguistics. Amsterdam: North-Holland: 267-287.

Milanez, W. (1993) Pedagogia do oral. Campinas: Sama

Mollica, M. C. (1996) Supra-segmentos de fronteira: principais causas e funções. In: TaVares, Roncarati \& Mollica (orgs.) Variação $e$ Discurso. Rio de Janeiro: Tempo Brasileiro: 129-147.

Mотsch, W. (ed.) (1987) Satz, Text, sprachliche Handlung. Berlim: Akademie Verlag.

Neis, I. A. (1981) Por uma gramática textual. Letras de Hoje, 44: 35-52. (1985) Por que uma lingüística textual? Letras de Hoje, 18(2): 7-12. (org.) (1985) Letras de Hoje, 18(2): Lingüística Textual. (1985) Elementos de tipologia do texto descritivo. Cadernos PUC 22: Lingüística Textual/ Texto e Leitura: 47-63.

Oliveira, H. F. (1996) Conectores da conjunção. In: L. W. dos Santos (org.) Discurso, coesão, argumentação. Rio de Janeiro: Oficina do Autor: 67-80.

OMEna, N. P. (1986) A referência variável da primeira pessoa do discurso no plural. In: A.NARo et alii. Relatório final de pesquisa: Projeto Subsídios do projeto censo à educação, Rio de Janeiro, UFRJ: 286319

Osakabe, H. (1979) Argumentação e Discurso Político. São Paulo: Kairós. Paiva, M. da C. (1996) Aspectos semânticos e discursivos da relação de causalidade. In: Tavares, Roncarati \& Mollica (orgs.) Variação $e$ Discurso. Rio de Janeiro; Tempo Brasileiro: 63-74

Paredes da Silva, V. L. (1985) É isso aí - verbo ser e demonstrativo em função coesiva em português. Anais do X Encontro Nacional de Lingüística. PUC/RJ.

Pauliukonis, M. A. L. (1996) Comparação e argumentação: duas noções complementares. In: L. W. dos Santos (org.) Discurso, Coesão, Argumentação. Rio de Janeiro: Oficina do Autor: 39-51

Pontes, E. (1987) O tópico no português do Brasil. Campinas: Pontes. (1986) Sujeito: da sintaxe ao discurso. São Paulo: Ática.

Preti, D. (org.) (1995) Análise de Textos Orais. São Paulo: FFLCH/USP. (1997) O Discurso Oral Culto. São Paulo: FFLCH/USP. \& H. Urbano (orgs.) (1990) A linguagem falada culta na cidade de São Paulo, Vol. IV: Estudos. São Paulo: T.A . Queiroz/Fapesp.

Rickheit, G. \& W. StTrohner (eds.) (1985) Inferences in text processing. Amsterdam: North-Holland. 
Risso, M. S. (1993) Agora... o que eu acho é o seguinte. In: A.T CAstilho (org.) Gramática do Português Falado, III: As Abordagens. Campinas: Edunicamp/Fapesp: 31-60.

(1966) O articulador discursivo ‘então'. In: CAstiLho \& BASílıo (orgs.) Gramática do Português Falado IV: Estudos Descritivos. Campinas: Edunicamp/Fapesp: 432-452

; G. M. de O. e Silva; H. Urbano (1997) Marcadores discursivos: traços identificadores. In: I. G. V. Кoch (org.) Gramática do Português Falado VI: Desenvolvimentos. Campinas: Edunicamp/Fapesp: 21-94. RonCARATI, C. N. (1991) Estruturas paralelas e combinação de cláusulas. Anais do IX Congresso Internacional da ALFAL. UNICAMP.

SÁ, M. P. M. (1997) A linguagem culta falada na cidade de Recife, V. I. Recife: Universidade Federal de Pernambuco.

Santos, L. W. (org.) (1996) Discurso, Coesão, Argumentação. Rio de Janeiro: Oficina do Autor.

Scherre, M. M. P. (1991) A concordância de número nos predicativos e particípios passados. Organon, 5, no 18: 52-70.

Schmidt, S. J. (1978) Lingüística e Teoria do Texto. São Paulo: Pioneira.

Schwarz, M. (1992) Einführung in die cognitive Linguistik. Tübingen: Franke.

Silveira, R. C. P. (1986) Um conceito de texto. Cadernos PUC 22: Lingüística textual/Texto e Leitura: 65-74.

Silva, G. M. O . \& A. T. de Macedo (1996) Análise sociolingüística de alguns marcadores conversacionais. In: Macedo, Roncarati \& Mollica (orgs.) Variação e discurso. Rio de Janeiro: Tempo Brasileiro: $11-50$.

Siqueira, J. H. S. (1986) As macrocategorias do texto dissertativo. Cadernos PUC 22: Lingüística de Texto/ Texto e leitura: 133-142.

Souza E SiLva, M. C. P. \& I. G. V. Косн (1996) Estratégias de desaceleração do texto falado. In: M. Kato (org.). Gramática do Português Falado, V: Convergências. Campinas: Edunicamp/Fapesp: 327-335.

\& M. F. de C. CRescitelli (1997) Sem querer interromper e... não interrompendo. In: I. C. V. Косн (org.) Gramática do Português Falado VI: Desenvolvimentos. Campinas: Edunicamp/Fapesp:149-159.

Travaglia, L. C. (1996) Tipologia textual e a coesão/coerência no texto oral: transições tipológicas. In: CAstilho \& BAsílio (orgs.) Gramática do Português Falado IV: Estudos Descritivos. Campinas: Edunicamp/ Fapesp: 453-472.

(1994) Categorias verbais e progressão textual. Revista de Letras da Universidad de Rosario: 35-52. 
VAn Disk, T. (1983) La Ciencia del Texto. Barcelona: Paidós. (1989) Models in memory. Ms.

(1994) Cognitive context models and discourse. Ms. \& W. KinTsCh (1983) Strategies of Discourse Comprehension. Nova Iorque: Academic Press.

Vignaux, G. (1991) Les Sciences Cognitives - Une Introduction. Paris: La Découverte.

Vogt, C. A. (1977) O Intervalo Semântico. São Paulo: Ática.

WeInRICH, H. (1964) Tempus: besprochene und erzählte Welt. Stuttgart Klett. $2^{\text {a }}$ edição: 1971. (1976) Sprache in Texten. Stuttgart: Klett. 